\title{
Effect of Cash Flow Forecasting on Financial Sustainability of SMEs in Kericho Central Business District.
}

\author{
Gilbert Turgut $^{1}$, Dr. Peter K. Cheruiyot ${ }^{2}$ Dr. Hellen W. Sang ${ }^{3}$ \\ ${ }^{1}$ (MBA, School of Business and Economics, University of Kabianga, Kenya) \\ ${ }^{2}$ (Lecturer, School of Business and Economics, University of Kabianga) \\ ${ }^{3}$ (Lecturer, School of Business and Economics, University of Kabianga) \\ DOI: 10.29322/IJSRP.11.10.2021.p11814 \\ http://dx.doi.org/10.29322/IJSRP.11.10.2021.p11814
}

\begin{abstract}
-
The study was guided by cash conversion cycle model and cash flow forecasting models. The study employed descriptive research design inform of survey. The target population of this study comprised 102 SME operators where a representative sample of 81 respondents was drawn. Simple random sampling was used in determining the final respondents. Primary data was collected from the respondents through structured questionnaires. Reliability and validity of data collection instruments was ascertained through test-retest method. Descriptive statistics like mean and standard deviation were used to summarize data. Inferential statistics such as correlation coefficients was used to test the non-causal relationship between variables while regression analysis was used to test the research hypotheses at 5\% significance level with the aid of SPSS version 25. There was agreement among respondents on whether they plan and priorities the payments of the expenses in order of importance and due dates. Further, there was agreement among the respondents on whether cash budget provides future-oriented information which facilitates monitoring and management of business performance. Conclusions can be made that SME operators are not able to project how and when cash would be received and spent. It was recommended that training be conducted to SME operators so that they are able to project how and when cash would be received and spent.
\end{abstract}

Index Terms- Cash flow, Forecasting, Financial Sustainability, Small and Medium Scale Enterprise

\section{INTRODUCTION}

A ccording to Effen and Johnson (2011), cash flow forecasting is not a matter of choice; it is one thing that has to be undertaken in any business. Small and Medium enterprises (SMEs) are essential supporters of the general execution of an economy, SMEs assume an imperative job in building up the economy and in making work, in this way giving business profits and chances to impact large number of people, and conjointly mechanically drive developments and economy expansion. There is no precise manner of determining the precise quantity of cash that make all SMEs to succeed (Moore, William \& Longernecker, 2010). Cash flow forecasting is important to each commercial enterprise that styles to meet up with its economic responsibilities. No commercial enterprise operation is isolative of cash management. Nick (2009) aforementioned that cash is considered the foremost crucial modern exceptional for the day to day running of businesses. Cash is that basic need in order to stay in the commercial enterprise as it forms a foundation for firms to focus on producing trade able goods and services and continue to expand and survive in a competitive business environment. Cash flow forecastingis paramount in every corporation as cash is alleged to be the existence blood line of any enterprise. The essence of cash flow forecasting is to affirm high quality income for any commercial enterprise operation. In line with Patel (2010) cash flow forecasting is concerned with the assurance of continuous flow of money to keep up the operations. It is considered the tradeoff between the danger and cost of holding a lot of money at the expense of safeguarding enterprise growth. So, there is the requirement for careful designing and looking of cash flows overtime on verify the best cash level to maintain.

Cash flow forecasting is necessary because of the reality that a lot of money is expensive, as one is paying interest on money that is not constantly needed. Too little cash is also luxurious; due to the fact that corporations are passing up decreases or potential outcomes on account of lost money or quietly exchanging the business existence by not re-stocking the enterprise due to lack of money (Raheman \& Nasr, 2007). Cash flow forecasting practices are the most significant assignment for business enterprise administrators. The business transforms into bankruptcy when it neglects to pay restored the obligations timorously, which is the main reason for money related ruin among little associations. The possibility of such a suggestion should weight organizations to effectively deal with their money with notice. Right cash flow forecasting is anticipated for developing beneficial and manageability of organizations. Legitimate and viable cash flow forecasting practices are basic to offsetting and settling dues and growing little gatherings. The income of a little endeavor should wind up precarious obligations while the business venture manages various customers who are difficult to deal with and keeping in mind that the undertaking moves stock to preferable and sought after over their rivals (Marsh, 2009).

In step with Abioro (2013), cash flow forecasting is equitably used to manage and decide the choicest level of money 
required for business activity and the interest in attractive securities, which is fitting for the idea of the enterprise operation cycle. The pattern of the money and working cycle fluctuates in line with enterprise, but in general time period, the sample entails the availability of cash as capital for company's startup capital, the sourcing of raw fabric in production by corporations and completed items in advertising by corporations, selling of the manufactured goods to be obtained immediately by customer buying them directly with money or taking them on credit thus having debtors when items are sold on credit score term. Moreover, the system of overseeing money has turn out to be a first-rate venture for in many organizations, due to its bigger sized effect on the enterprise. The fulfillment of successful enterprise is expected to manage, plan and manage it cash flows (John, 2012). Powerful management of money is an essential factor so as to ensure that the company's finances are in sturdy role. Similarly, management of cash could be critical also in manufacturing companies whose assets normally entails present day belongings (Mohd \& Mat, 2013). According to Raheman and Nasir (2007) Cash flow forecasting without delaying have impact on liquidity. Effective money management contributes without a doubt to the execution of enterprises and their survival.

Small and Medium Scale Enterprises (SMEs) "are a key supply of dynamism, innovation and flexibility in superior industrialized nations, in addition as in growing countries, they may be typically delineated as effective and prolific task creators, the seeds of big SMEs and therefore the gas of national financial technique. Even inside the advanced commercial economies, it is the SMEs quarter instead of the multinationals that is the maximum important chief of body of workers (Abioro, 2013). Most SME operators do not have basic cash flow forecasting skills like accounting, cash and inventory management skills; hence they find themselves losing track of their daily transactions and cannot account for his or her expenses and profits at the end of the month which may even threaten their survival further. Also, most of them do not interact their capital in such the way on realize most profit (Effen \& Johnson, 2011).

The main objective of cash flow forecasting is to make sure the upkeep of satisfactory level of cash in every means that may forestall excessive or inadequate handiness of capital. It is necessary to notice that inefficient cash flow forecasting scale back gain in an enterprise and cause cash crises and its associated effects (Velnamby and Kajananthan, 2013). In line with John (2014), management of cash is very important for the cash health of all businesses, no matter kind and size. Specifically, this study sought to establish the impact of cash flow forecasting practices on the financial sustainability of SMEs.

\section{PROBlEM STATEMENT}

Cash flow forecasting provides vital insight into the state of SMEs cash position and its importance to the success of SMEs cannot be under calculated. One amongst the intense challenges faced by most business managers is a way to effectively and with efficiency manage benefits in order to maximize their profits and guarantee financial sustainability. This can be as a result of cash flow forecasting practices that are inter-twinned and their management is tough since these are often connected. Hence, fixing one item might impact adversely upon alternative areas of the business. These include; cash flow forecasting, liquidity management, budget management and cash control. Inadequate skills in management of cash results in attendant cash flow problems which reduces SMEs financial sustainability and invariably leads to financial crises coupled with its associated effects. However, all the efforts and interventions by SME operators are put to a halt by the problems affecting their SME growth and financial sustainability. Therefore, this research work sought to fill the knowledge gap by examining the effect of cash flow forecasting on financial sustainability of SMEs in Kericho County an area that has not been empirically investigated thus forming a fundamental basis of the proposed study."

\section{CASH ManaGement Models}

Effective cash management approach will inescapably realize surplus money over the money wants of the firm. It is along these lines' imperative for the financial manager to choose the most productive dimension of money to safeguard all together that the additional can be changed over into "close to cash" One fundamental duty of the budgetary administrator, with regards to Pandey (2008), is to protect the reasonable dimension of liquidity inside the organization to such an extent that money related commitments can be identified while it is miles to be due. Enterprises should be equipped for set up the fitting dimension of money equalization to be held by methods for the organization anytime and this is by and large spurred by the change - offs among threat and returns. As Gallagher (2000), places it, "cash management entails an alternate-off between the need for liquidity and choice for profitability. The more a firm holds cash, the extra liquid it becomes, however piling up budget to maintain liquidity will prevent fund from being invested in long term, high generating property" The firm is, hence, anticipated to save an ideal money steadiness that is neither too little nor huge. A money balance is expressed to be in its most proper capacity while the exchange cost and danger of keeping little money balance is equivalent to the likelihood cost of safeguarding bigger money dependability. economic scholars have developed scientific models to help organizations locate a prevalent "target" money balance, among the negligible and most extreme points of confinement, which likens liquidity to productivity (Kytonen, 2004).

\section{Conceptual Framework}

A conceptual framework shows a hypothesized representation that depicts the relationship between variables (Mugenda and Mugenda, 2008). The model will help provide the link between the independent variables (cash forecasting) and the dependent variable (financial sustainability).
Independent Variable

\section{Cash flow forecasting}

- confidence of the bankers

- cash projection

- identify potential cash problems
Dependent Variable

\section{Financial sustainability}

- $\quad$ sound cash position 


\section{RESEARCH DESIGN}

A descriptive survey research design is used in this study. Kothari, (2009) notes that a descriptive research design is used when data is collected to describe persons, organizational settings or phenomenon. This is supported by (Mugenda \& Mugenda, 2008) who states that this type of design enables one to obtain information with sufficient precision so that hypothesis can be tested properly. According to Easterby-Smith, Thorpe and Jackson (2008), (2006), descriptive surveys are interested in addressing specific characteristics of a selected population of subjects at a point in time, or at varying times for the purpose of comparing the relationship between variables. The research design was chosen because it is the most appropriate method when the researcher seeks to study the phenomenon being studied and the relationship between variables.

\section{Descriptive results for Cash Forecasting}

\section{Validity and Reliability of instruments}

Data collection equipment (questionnaires) will be verified previous to facts collection workout. In step with Mugenda and Mugenda (2003), validity is the way to which ends up acquired from the evaluation of the records certainly represents the phenomenon under study. Cronbach's Coefficient Alpha was used to ascertain internal consistency reliability. All the variables reported Cronbach's Coefficient Alphas greater than 0.7 and were deemed reliable. According to Kombo and Tromp (2006), alpha value of 0.7 or higher indicates flawed reliability and internal consistency.

\section{RESUltS AND DisCUSSION}

\section{Descriptive analysis for Cash Forecasting}

Respondents were asked to indicate their agreement on the following items relating to cash forecasting. The results are presented in table 4.4 .
Statements

cash flow plan increases the confidence of the bankers on the systems and managements and fits the criteria for banks to66 evaluate and consider funding

Am able to project how and when cash would be received and 66 spent

66

I able to identify potential cash problems and deciding on how 66 to adjust it to improve the organizations cash position

Cash flow is only derived once the difference is distinguished66 between sales revenue and cash receipts

The cash flow forecast duration is flexible

66

I often keep up to date cash flow statement for my business
Mean

3.742

3.697

3.364

3.848

3.848

3.609
Standard deviation

1.099

1.123

1.223

1.256

1.041

0.932

\section{Average Score}

66

0.785

On cash forecasting, the results on table 4.4 indicate that majority of the respondents were in agreement that cash flow plan increases the confidence of the bankers on the systems and managements and fits the criteria for banks to evaluate and consider funding $($ mean=3.742, $\mathrm{SD}=1.099)$. There was disagreement among most respondents on whether they were able to project how and when cash would be received and spent (mean=3.697, $\mathrm{SD}=1.123$ ). Respondents showed neutral opinion on whether they were able to identify potential cash problems and deciding on how to adjust it to improve the organizations cash position (mean=3.364, $\mathrm{SD}=1.223$ ). There was neutrality in opinion among the respondents on whether cash flow is only derived once the difference is distinguished between sales revenue and cash receipts (mean=3.151, $\mathrm{SD}=1.256$ ). Respondents were in agreement that the cash flow forecast duration is flexible (mean=3.849, $\mathrm{SD}=1.041$ ). There was also agreement among the respondents on whether they often kept up to date cash flow statement for their business (mean $=3.849$, $\mathrm{SD}=0.932$ ).

Nearly all the statements had responses had mean values with standard deviations greater than 1 . This implies that there was disparity in the opinions among the respondents regarding those individual statements. The aggregate mean score $($ mean $=3.609)$ indicates that most respondents were in agreement 
with cash forecasting statements. The average mean score reported a standard deviation less than $1(\mathrm{SD}=0.785)$. This indicates that on average, respondents had similar opinion regarding cash forecasting statements.

\section{MUlTIPLE REGRESSION}

Multiple regression analysis was run to test formulated research hypotheses. The study sought to examine the combined effect of all predictor variables on the dependent variable. Table 4.10 shows that the overall $\mathrm{R}^{2}=0.525$ which indicates 52.5 percent of the variation in the dependent variable is explained by the independent variable. The remaining $47.5 \%$ variation in the dependent variable is explained by other factors not included in the model denoted by $(\varepsilon)$ in the model

Table 4.10: Model Summary

\begin{tabular}{|c|c|c|c|c|c|c|c|}
\hline \multirow[b]{3}{*}{ Model R } & \multicolumn{7}{|c|}{ Change Statistics } \\
\hline & & Adjusted & RStd. Error $\mathrm{c}$ & ofR $\mathrm{S}$ & Square & & \\
\hline & R Square & Square & the Estimate & Change & F Change df1 & df2 & Change \\
\hline $1 \quad .570^{\mathrm{a}}$ & .525 & .281 & .09266 & .525 & $7.349 \quad 4$ & 61 & .000 \\
\hline
\end{tabular}

As presented on table 4.11, the mean square of the residuals is very small compared to mean square of the regression. Further, the F-statistics of the regression $\left(F_{(4,61)}\right.$ $=27.769)$ which is statistically significant $(p<0.05)$ indicates that the model applied significantly predict the change of the dependent variable as result of the predictor variables included in the model. This implies that the coefficients of the model are not equal to zero, suggesting that the model fits the data significantly.

Table 4.12: Coefficients

\begin{tabular}{|c|c|c|c|c|c|c|}
\hline \multirow[b]{2}{*}{ Model } & & \multicolumn{2}{|c|}{ Unstandardized Coefficients } & \multicolumn{2}{|l|}{$\begin{array}{l}\text { Standardized } \\
\text { Coefficients }\end{array}$} & \multirow{3}{*}{$\begin{array}{l}\text { Sig. } \\
.027\end{array}$} \\
\hline & & B & Std. Error & Beta & $\mathrm{T}$ & \\
\hline 1 & (Constant) & 1.285 & .566 & & 2.271 & \\
\hline & $\begin{array}{l}\text { Cash } \\
\text { Forecasting }\end{array}$ & flow.500 & .155 & .681 & 4.519 & .000 \\
\hline
\end{tabular}

As presented on table 4.12, the beta coefficient for cash flow forecasting was 0.500 with p-value $<0.05$. This means that when cash flow forecasting increases by an additional unit, financial sustainability of SMEs increases by 0.5 units. Thus, the null hypothesis $\left(\mathbf{H}_{\mathbf{0 1}}\right)$ was rejected implying that cash flow forecasting has significant effect on financial sustainability of SMEs in Kericho Central Business District. The results are consistent with those of Okwena et al (2011), who conducted found that cash flow forecasting enhance operational and financial sustainability of firms.

\section{SUMMARY}

The Purpose of the study was to establish the effect of cash flow forecasting on financial sustainability of SMEs in Kericho Central Business District. Data was collected using questionnaires and analyzed using descriptive and inferential statistics. Respondents were in agreement that cash flow plan increases the confidence of the bankers on the systems and managements and fits the criteria for banks to evaluate and consider funding. There was disagreement among most respondents on whether they were able to project how and when cash would be received and spent. Respondents showed neutral opinion on whether they were able to identify potential cash problems and deciding on how to adjust it to improve the organizations cash position. There was neutrality in opinion among the respondents on whether cash flow is only derived once the difference is distinguished between sales revenue and cash receipts. Respondents were in agreement that the cash flow forecast duration is flexible. There was also agreement among the respondents on whether they often kept up to date cash flow statement for their business. The results indicate that there exist a significant positive relationship between cash flow forecasting and financial sustainability of SMEs in Kericho Central Business District

\section{CONCLUSIONS}

Conclusions can be that cash flow forecasting has a significant effect on financial sustainability of SMEs in Kericho Central Business District. It can be concluded that cash flow plan increases the confidence of the bankers on the systems and managements and fits the criteria for banks to evaluate and consider funding. Conclusions can be made that SME operators are not able to project how and when cash would be received and spent. Conclusions can be made that SME operators are not able 
to identify potential cash problems and deciding on how to adjust it to improve the organizations cash position. It was not also clear on whether cash flow is only derived once the difference is distinguished between sales revenue and cash receipts. It can be concluded that the cash flow forecast duration is flexible and that SME operators often kept up to date cash flow statement for their business.

\section{RECOMMENDATIONS}

It was recommended that training be conducted to SME operators so that they are able to project how and when cash would be received and spent. The training will also be able to help SME operators identify potential cash problems which will help them adjust to improve the organizations cash position. Through training SMEs will also be able to distinguish between sales revenue and cash receipts.

\section{REFERENCES}

[1] Abioro, M. (2013), The impact of cash management on the performance of manufacturing companies in Nigeria. Journal of Supply Chain Management, 1(3), 177-192

[2] Easterby-smith, M., Thorpe, R., \& Jackson, P. R., (2008). Management Research. London: Sage Publications Ltd.

[3] Effen, J.J., Johnson, A.C. (2011). Cash conversion cycle management in Small firms; Relationship with liquidity, invested capital and firm performance. Journal of Small Business and Entrepreneurship, 24 (3), 381-396

[4] Gallagher, T. (2000). Financial Management Principle \& Practice, 2nd Edition New Jersey: Prentice Hall Inc.

[5] John, K. M. (2012), "Cash Management Practices of Small Business Owners in the Cape Coast Metropolitan Area of Ghana". Asian Economic and Financial Review, 2 (1), $40-58$.

[6] Kombo, D., \& Tromp, L. (2008). Research Methods: Nairobi Kenya; Kenyatta University.
[7] Kothari, C. R. (2009). Research Methodology; Methods and techniques (2nd Ed.) New Delhi. New Age International Limited Publishers.

[8] Kytonen, E. (2004). The cash management behavior of firms and its structural change in an emerging cash market. Proceedings of the University of Oulu.

[9] Mohd, K. H., \& Mat S. A., (2013). "A proposed framework for redefining SMES in Malaysia: One industry one definition? Universiti Teknologi Mara

[10] Mong, D. (2011). Follow the cash: Lessons for Capstone business courses. Journal of business \& Economics research, 9(12), 33-44.

[11] Moore, J., William, P., \& Longernecker, J. (2010). Managing Small business: An entrepreneural emphasis. 15th ed. Australia: SouthWestern/Cengage Learning.

[12] Mugenda, O. M. \& Mugenda, A. G. (2008), Research Method Quantitative \&Qualitative Approaches: Nairobi Kenya: acts Press.

[13] Nick, S. (2009). Cashflow ignorance is big problem for firms. Domimion Press, Turkey.

[14] Pandey, I.M., (2008). Financial Management, 9th Edition, Vikas Publishing Business PVT.

[15] Patel, U. (2010). Cash Management at Indian oil Corporation Ltd. Master's in business administration, Diyil press. Patil University.

[16] Raheman, A., \& Nasri, M. (2007). Working Capital Management and profitability - case of Pakistani Firms. International Review of Business Research papers, 3 (1), 279-300

[17] Velnamby T. Kajananthan, D. (2013). Cash position and profitability of Telcommunication sector in Sri Lanka, Effectives Journal of Social Sciences, 3(6), 324-333.

\section{AUTHORS}

First Author - Gilbert Turgut, MBA, School of Business and Economics, University of Kabianga, Kenya

Second Author - Dr. Peter K. Cheruiyot, Lecturer, School of Business and Economics, University of Kabianga

Third Author - Dr. Hellen W. Sang, Lecturer, School of Business and Economics, University of Kabianga 